\title{
Natural history of patients with venous thromboembolism and hereditary hemorrhagic telangiectasia. Findings from the RIETE registry
}

Antoni Riera-Mestre ${ }^{1,2^{*}}$ (D) José María Mora-Luján ${ }^{1}$, Javier Trujillo-Santos ${ }^{3}$, Jorge Del Toro ${ }^{4}$, José Antonio Nieto ${ }^{5}$, José María Pedrajas ${ }^{6}$, Raquel López-Reyes ${ }^{7}$, Silvia Soler ${ }^{8}$, Aitor Ballaz ${ }^{9}$, Pau Cerdà ${ }^{1}$, Manel Monreal ${ }^{10}$ and the RIETE Investigators

\begin{abstract}
Background: Limited data exist about the clinical presentation, ideal therapy and outcomes of patients with hereditary hemorrhagic telangiectasia (HHT) who develop venous thromboembolism (VTE).
\end{abstract}

Methods: We used the data in the RIETE Registry to assess the clinical characteristics, therapeutic approaches and clinical outcomes during the course of anticoagulant therapy in patients with HHT according to initial presentation as pulmonary embolism (PE) or deep venous thrombosis (DVT).

Results: Of 51,375 patients with acute VTE enrolled in RIETE from February 2009 to January 2019, 23 (0.04\%) had HHT: 14 (61\%) initially presented with PE and 9 (39\%) with DVT alone. Almost half (47.8\%) of the patients with VTE had a risk factor for VTE. Most PE and DVT patients received low-molecular-weight heparin for initial (71 and 100\%, respectively) and long-term therapy (54 and 67\%, respectively). During anticoagulation for VTE, the rate of bleeding events (major 2, non-major 6) far outweighed the rate of VTE recurrences (recurrent DVT 1): 50.1 bleeds per 100 patient-years (95\%Cl: 21.6-98.7) vs. 6.26 recurrences (95\%Cl: 0.31-30.9; $p=0.020)$. One major and three non-major bleeding were epistaxis. No patient died of bleeding. One patient died shortly after being diagnosed with acute PE.

Conclusions: During anticoagulation for VTE in HHT patients, there were more bleeding events than VTE recurrences. Most bleeding episodes were non-major epistaxis.

Keywords: Deep venous thrombosis, Hemorrhagic hereditary telangiectasia, Pulmonary embolism, Rare diseases, Venous thromboembolism

\section{Introduction}

Hereditary hemorrhagic telangiectasia (HHT) or RenduOsler-Weber disease is a rare vascular genetic disorder with an estimated prevalence of one in 6000 individuals $[1,2]$. Patients with HHT have cutaneous telangiectasia, mostly in the fleshy part of the hands, or in the oral, nasal or gastrointestinal (GI) mucosa, and large

\footnotetext{
* Correspondence: ariera@bellvitgehospital.cat

${ }^{1}$ HHT Unit and VTE Unit, Internal Medicine Department, Hospital Universitari de Bellvitge, Bellvitge Biomedical Research Institute (IDIBELL), C/ Feixa Llarga $\mathrm{s} / \mathrm{n}$. L'Hospitalet de Llobregat, 08907 Barcelona, Spain

${ }^{2}$ Faculty of Medicine and Health Sciences, Universitat de Barcelona,

Barcelona, Spain

Full list of author information is available at the end of the article
}

arteriovenous malformations (AVMs), mostly in the lungs or liver $[3,4]$. These patients may suffer from many complications including bleeding, anemia, iron deficiency, stroke and high-output heart failure [4-6].

The diagnosis of HHT is established on clinical criteria, according to the Curaçao criteria: recurrent epistaxis, cutaneous/mucosal telangiectasia, visceral involvement, and a first line family member with HHT [7]. The diagnosis may be further confirmed by the identification of causative mutations mostly in either the ENG (endoglin) or the ACVRL1 (activin A receptor type II-like 1) genes coding for endoglin and activin receptorlike kinase-1, respectively [2]. These proteins are 
involved in the vascular signaling pathway of the transforming growth factor (TGF)-beta family [2, 8]. Recurrent epistaxis is the most common symptom, appearing in around $95 \%$ of HHT patients by 50 years of age [3, 4, 9]. Although recurrent bleeding events are the hallmark, some patients with HHT may also develop venous thromboembolism (VTE) [9-11]. HHT patients with acute venous thromboembolism (VTE) are perceived to be at high risk for major bleeding if anticoagulant therapy is prescribed, but the evidence on this issue is scarce and based on online interviews [12,13].

The RIETE (Registro Informatizado Enfermedad TromboEmbólica) registry is an ongoing, multicenter, observational registry of consecutive patients with objectively confirmed acute VTE (ClinicalTrials.gov identifier: NCT02832245). Data from this registry have been used to evaluate outcomes after acute VTE, such as the frequency of recurrent VTE, major bleeding or mortality, and risk factors for these outcomes [14-16]. The rationale and methodology of RIETE have been published elsewhere [17]. In the current study, we aimed to assess the clinical characteristics, therapeutic approaches and clinical outcomes of patients with HHT and VTE, according to initial presentation as pulmonary embolism (PE) or deep venous thrombosis (DVT).

\section{Methods}

\section{Inclusion criteria}

Consecutive patients with acute, symptomatic DVT or PE confirmed by objective tests (compression ultrasonography or contrast venography for DVT; helical CTscan of the chest, ventilation-perfusion lung scintigraphy or angiography for PE) were enrolled in RIETE. Patients were excluded if they were currently participating in a blind therapeutic clinical trial. All patients (or their relatives) provided written or oral consent for participation in the registry, in accordance with local ethics committee requirements.

\section{Study design}

For this study, only patients with HHT were considered. This information was added to the RIETE data abstraction forms in February 2009. Therefore, only patients recruited after this date were eligible for the current study. Collected data were appropriately made anonymous and each patient was identified by a unique alphanumeric identification code. HHT patients were divided according to VTE index event as PE or DVT. Primary outcome was the risk for VTE recurrences and major or nonmajor bleeding occurring during the course of anticoagulation. Secondary outcomes were fatal PE and fatal bleeding. Bleeding events were classified as 'major' if they were overt and required transfusion of two or more red blood cell units, or were retroperitoneal, spinal or intracranial. All clinically evident bleeding not considered major, were classified as 'non-major'. Fatal PE, in the absence of autopsy, was defined as any death appearing $<10$ days after PE diagnosis, in the absence of any alternative cause of death. Fatal bleeding was defined as any death occurring $<10$ days after a major bleeding episode, in the absence of any alternative cause of death. For preparation of this manuscript, we followed the Strengthening the Reporting of Observational Studies in Epidemiology (STROBE) statement guidelines for observational cohort studies [18].

\section{Study variables}

The following parameters were recorded in RIETE: patient's baseline characteristics; clinical status including any coexisting or underlying conditions, recent major bleeding, anemia or renal insufficiency; risk factors for VTE; the treatment received upon VTE diagnosis; concomitant drugs and the outcomes during the course of therapy. For normotensive patients with PE, stratification using the simplified version of the Pulmonary Embolism Severity Index (sPESI) was assessed [15]. Immobilized patients were defined as non-surgical patients who had been immobilized (i.e., total bed rest with or without bathroom privileges) for $\geq 4$ days in the 2 month period prior to VTE diagnosis. Surgical patients were defined as those who had undergone an operation in the 2 months prior to VTE. Active cancer was defined as newly diagnosed cancer ( $<3$ months before) or when receiving anti-neoplastic treatment of any type (i.e., surgery, chemotherapy, radiotherapy or hormonal therapies). Recent bleeding was considered in those patients suffering major bleeding < 30 days prior to VTE. Anemia was defined as hemoglobin levels $<13 \mathrm{~g} / \mathrm{dL}$ for men and $<12 \mathrm{~g} / \mathrm{dL}$ for women.

\section{HHT additional information}

When preparing this study, we attempted to gather as much specific information on HHT as possible, through personal communication with the attending doctors. The study coordinating center contacted with the investigators and tried to retrospectively calculate the Epistaxis Severity Score (ESS) at the index VTE event. ESS is an on-line tool that estimates the severity of epistaxis according to clinical data occurring during last 3 months. Epistaxis is considered moderate or severe if ESS results $>4$ or $>7$ points, respectively [19]. We also attempted to assess the genetic study for HHT, specifically for mutations in ENG or ACVRL1 genes, and information about the Curaçao criteria $[2,7,8]$.

\section{Treatment and follow-up}

Patients were managed according to the clinical practice of each participating hospital (i.e., there was no 
standardization of treatment). The type, dose and duration of anticoagulant therapy were recorded. After VTE diagnosis, all patients were followed-up in the outpatient clinic for at least 3 months. During each visit, any signs or symptoms suggesting VTE recurrences or bleeding complications were noted. Each episode of clinically suspected recurrent VTE was investigated by using diagnostic tests as appropriate. Most outcomes were classified as reported by the clinical centers. However, if staff at the coordinating center were uncertain how to classify a reported outcome, that event was reviewed by a central adjudicating committee (less than $10 \%$ of events).

\section{Statistical analysis}

Categorical variables were compared between PE and DVT patients with HHT using the chi-square test (twosided) and Fisher's Exact Test (two-sided). Odds ratio (and its 95\% confidence interval) was calculated for categorical variables. Continuous variables were compared using Student $t$ test. The incidence rate of adverse events was calculated as events per 100 patient-years of treatment and compared, according to the initial presentation of the VTE episode (PE vs. DVT), as rate ratios, both with a $95 \%$ confidence interval. A $P$-value of $<0.05$ was chosen as the cut off for statistical significance. Statistical analyses were conducted using SPSS for Windows Release (version 20, SPSS Inc. Chicago, Illinois).

\section{Results}

Of 51,375 patients enrolled in RIETE from February 2009 to January 2019, 23 (0.04\%) had HHT. Of these, 13 (56.5\%) were male, mean age was $61 \pm 17$ years, 14 (61\%) presented initially with PE and 9 (39\%) presented with DVT alone. Eighteen patients (78\%) had a history of recurrent epistaxis, and three (13\%) had suffered a major bleeding (all epistaxis) in the last 30 days before the index VTE event. There was available information to calculate the ESS in 16 (69\%) patients, and mean ESS was $4.4 \pm 2.4$ (0. 9-8.4) points. Genetic study was positive for ENG in 5 (22\%) patients, for ACVRL1 in 2 (9\%) and one (4.5\%) patient had negative results (but had 3 of 4 Curaçao criteria).

Six patients (26\%) developed the VTE after being immobilized for $\geq 4$ days (because of decompensated chronic lung disease 2, trauma 2, ischemic stroke 1, pneumonia 1), two (9\%) after undergoing surgery (hernia disc repair 1 , hip fracture 1$)$, one patient $(4.5 \%)$ had cancer and two (9\%) had a history of prior VTE. Only three patients had received prophylaxis before the index VTE: two patients admitted in the hospital because of decompensated chronic lung disease and one patient with hip fracture. Twelve (52\%) patients had anemia at baseline, six $(26 \%)$ had creatinine clearance levels $<60 \mathrm{~mL} / \mathrm{min}$, three (13\%) had angiodysplasia in the GI tract and one
(4.5\%) patient had a GI ulcer. All patients had normal prothrombin test and activated partial thromboplastin time. There were no significant differences in the clinical characteristics between patients who initially presented with PE or DVT. All 14 patients initially presenting with PE were admitted in hospital and 7 (50\%) were considered to be at high risk according to sPESI score (Table 1).

Median duration of anticoagulant therapy was 203 days in patients with PE and 164days in those with DVT. Most (71\%) PE and all (100\%) DVT patients were initially treated with low-molecular-weight heparin (LMWH), but four (29\%) and two (22\%) patients respectively received less than $100 \mathrm{IU} / \mathrm{kg} /$ day. Among the remaining patients with $\mathrm{PE}$, two (14\%) were prescribed unfractionated heparin, one (7\%) rivaroxaban and one (7\%) patient received an inferior vena cava filter without anticoagulant therapy. For long-term therapy, 7 (54\%) PE patients and 6 (67\%) DVT patients continued on long-term LMWH therapy, but one (8\%) and two (22\%) of these patients received less than $100 \mathrm{IU} / \mathrm{kg} /$ day, respectively. Among the remaining patients, five (38\%) and three (33\%) switched to vitamin $\mathrm{K}$ antagonists (VKAs), respectively, and one (8\%) PE patient continued on rivaroxaban (Table 2).

During the course of anticoagulation, (mean, $260 \pm$ 254 days for PE and $243 \pm 195$ days for DVT), the rate of bleeding events (major bleeding 2 episodes, non-major 6) far outweighed the rate of VTE recurrences (recurrent DVT one episode): 50.1 bleeds per 100 patient-years (95\%CI: 21.6-98.7) vs. 6.26 recurrences (95\%CI: $0.31-$ $30.9 ; p=0.020)$. One patient had a major bleeding in the GI tract 534 days after PE diagnosis while receiving VKAs, and one patient had a major epistaxis 32 days after the diagnosis of DVT while receiving LMWH at < $100 \mathrm{IU} / \mathrm{kg} /$ day. Three non-major bleeds were epistaxis. All four patients with epistaxis had an ESS $>4$. No patient died of bleeding. Among DVT patients, one patient presented a DVT recurrence 227 days after the diagnosis, while receiving vitamin $\mathrm{K}$ antagonists. One patient died of respiratory insufficiency due to hospital-acquired pneumonia 4 days after being diagnosed with acute PE, while receiving unfractionated heparin. She did not undergo repeat tests to exclude recurrent PE, so we cannot rule out the diagnosis of fatal PE (Table 3 ).

\section{Discussion}

Since HHT is a rare disorder, the natural history of VTE in these patients, and the optimal therapy are not well known. The only two studies that analyze the effect of anticoagulation in HHT patients were not based on objectively confirmed diagnosis and outcomes of VTE but on on-line surveys $[12,13]$. The first one was an on-line questionnaire about the use of antiplatelet or 
Table 1 Clinical characteristics of 23 patients with HHT and acute VTE

\begin{tabular}{|c|c|c|c|}
\hline & Pulmonary embolism & Deep vein thrombosis & $\begin{array}{l}\text { Odds ratio }(95 \% \mathrm{CI}) / \\
P \text { value }\end{array}$ \\
\hline Patients, $N$ & 14 & 9 & \\
\hline \multicolumn{4}{|l|}{ Clinical characteristics, } \\
\hline Male gender & $6(43 \%)$ & $7(78 \%)$ & $0.21(0.03-1.43)$ \\
\hline Mean age (years $\pm S D$ ) & $60 \pm 16$ & $62 \pm 19$ & $P=0.708$ \\
\hline Mean body weight ( $\mathrm{kg} \pm \mathrm{SD})$ & $87 \pm 28$ & $72 \pm 9.7$ & $P=0.145$ \\
\hline \multicolumn{4}{|l|}{ Data on $\mathrm{HHT}_{,}^{\mathrm{a}}$} \\
\hline Spontaneous, recurrent epistaxis $(n=18)$ & $12(86 \%)$ & $6(67 \%)$ & \\
\hline Epistaxis severity score ( $n=9$ and 7$)$ & $3.5(0.9-8.4 ; \pm 2.1)$ & $5.4(2.7-8.1 ; \pm 2.3)$ & $P=0.097$ \\
\hline $\mathrm{ESS}>4$ & $3(21 \%)$ & $4(44 \%)$ & $P=0.615$ \\
\hline ESS $>7$ & $1(7 \%)$ & $3(33 \%)$ & $P=0.262$ \\
\hline \multicolumn{4}{|l|}{ Genetic study $(n=11)$} \\
\hline ENG mutations & $2(14 \%)$ & $3(33 \%)$ & \\
\hline ACVRL1 mutations & $1(7 \%)$ & $1(11 \%)$ & \\
\hline Negative & $1(7 \%)$ & 0 & \\
\hline Family history $(n=16)$ & $10(71 \%)$ & $6(67 \%)$ & \\
\hline \multicolumn{4}{|l|}{ Risk factors for $V T E}$, \\
\hline Recent surgery & $1(7 \%)$ & $1(11 \%)$ & $0.62(0.03-11.28)$ \\
\hline Recent immobilization $\geq 4$ days & $4(29 \%)$ & $2(22 \%)$ & $1.40(0.20-9.87)$ \\
\hline Cancer & $1(7 \%)$ & 0 & - \\
\hline Prior VTE & $1(7 \%)$ & $1(11 \%)$ & $0.62(0.03-11.28)$ \\
\hline None of the above & $6(43 \%)$ & $6(67 \%)$ & $0.38(0.07-2.15)$ \\
\hline \multicolumn{4}{|l|}{ Underlying conditions, } \\
\hline Prior ischemic stroke & $3(21 \%)$ & 0 & - \\
\hline Atrial fibrillation & $3(21 \%)$ & 0 & - \\
\hline Gastroduodenal ulcer & $1(7 \%)$ & 0 & - \\
\hline Angiodisplasia in the Gl tract & $3(21 \%)$ & 0 & - \\
\hline Recent ( $<30$ days) major bleeding & 0 & $3(33 \%)$ & - \\
\hline \multicolumn{4}{|l|}{ Laboratory data, } \\
\hline Anemia & $6(43 \%)$ & $5(56 \%)$ & $0.60(0.11-3.25)$ \\
\hline $\mathrm{CrCl}$ levels $<30 \mathrm{~mL} / \mathrm{min}$ & 0 & 0 & - \\
\hline CrCl levels $30-60 \mathrm{~mL} / \mathrm{min}$ & $2(14 \%)$ & $3(33 \%)$ & $0.33(0.04-2.56)$ \\
\hline \multicolumn{4}{|l|}{ sPESI, } \\
\hline$\geq 1$ points & $7(50 \%)$ & - & - \\
\hline
\end{tabular}

Abbreviations: SD standard deviation, HHT hemorrhagic hereditary telangiectasia, ENG endoglin gene, ACVRL1 activin A receptor type II-like 1 gene, VTE venous thromboembolism, Gl gastrointestinal, sPESI simplified version of the Pulmonary Embolism Severity Index, $\mathrm{CrCl}$ creatinine clearance levels; $95 \% \mathrm{Cl}, 95 \%$ confidence intervals

${ }^{a}$ Retrospective information added, not included in the RIETE Registry

anticoagulant agents in HHT patients [12]. A worsening of their usual epistaxis was referred in 86 (57.3\%) of 150 patients with HHT who received anticoagulant therapy for different reasons [12]. In the second study, $20 \%$ of 20 patients with self-reported diagnosis of VTE who received anticoagulant therapy had to withdraw anticoagulation because of bleeding [13].

Our findings, obtained from the largest series of HHT patients with objectively confirmed VTE, reveal that one in every $3(35 \%)$ patients bled during the course of anticoagulant therapy, though no bleed was fatal. This may be due to the fact that most bleeds came from nasal or GI tract telangiectasia and not from large vascular malformations (i.e. in the liver, lung or brain), that are common in HHT patients. The ESS seems to detect those patients at an increased risk to develop epistaxis, as all four patients with epistaxis during anticoagulation had a ESS $>4$. ENT management to optimize measures to reduce epistaxis could allow to better tolerate anticoagulation $[3,20]$. Other options, such as tranexamic acid, topical or systemic estrogens, thalidomide or bevacizumab, should be weighted against the risk of VTE for these drugs [3, 21-24]. 
Table 2 Treatment strategies

\begin{tabular}{|c|c|c|c|}
\hline & $\begin{array}{l}\text { Pulmonary } \\
\text { embolism }\end{array}$ & $\begin{array}{l}\text { Deep vein } \\
\text { thrombosis }\end{array}$ & $\begin{array}{l}\text { Odds ratio } \\
(95 \% \text { Cl) / } \\
P \text { value }\end{array}$ \\
\hline Patients, N & 14 & 9 & \\
\hline \multicolumn{4}{|l|}{ Duration of therapy, } \\
\hline Mean days (SD) & $260 \pm 254$ & $243 \pm 195$ & $P=0.867$ \\
\hline Median days (IQR) & $171(111-335)$ & $177(86-475)$ & $P=0.999$ \\
\hline \multicolumn{4}{|l|}{ Initial therapy, } \\
\hline Unfractionated heparin & $2(14 \%)$ & 0 & - \\
\hline Low-molecular-weight heparin & $10(71 \%)$ & $9(100 \%)$ & - \\
\hline Mean LMWH dose (IU/kg/day) & $132 \pm 50$ & $151 \pm 59$ & $P=0.474$ \\
\hline LMWH doses $<100 \mathrm{IU} / \mathrm{kg} /$ day & $4(29 \%)$ & $2(22 \%)$ & $2.33(0.31-17.55)$ \\
\hline Rivaroxaban & $1(7 \%)$ & 0 & - \\
\hline Inferior vena cava filter (without anticoagulant therapy) & $1(7 \%)$ & 0 & - \\
\hline Long-term therapy, & 13 & 9 & \\
\hline Low-molecular-weight heparin & $7(54 \%)$ & $6(67 \%)$ & $0.58(0.10-3.40)$ \\
\hline Mean LMWH dose (IU/kg/day) & $135 \pm 35$ & $119 \pm 43$ & $P=0.491$ \\
\hline LMWH < 100 IU/kg/day & $1(8 \%)$ & $2(22 \%)$ & $0.27(0.02-3.52)$ \\
\hline Vitamin $\mathrm{K}$ antagonists & $5(38 \%)$ & $3(33 \%)$ & $1.25(0.21-7.41)$ \\
\hline Rivaroxaban & $1(8 \%)$ & 0 & - \\
\hline No anticoagulant drugs & 0 & 0 & - \\
\hline
\end{tabular}

Abbreviations: SD standard deviation, IQR interquartile range, $L M W H$ low-molecular-weight heparin, IU international units, 95\%Cl, 95\% confidence intervals

Table 3 Clinical outcomes during the course of anticoagulant therapy

\begin{tabular}{|c|c|c|c|c|c|}
\hline & \multicolumn{2}{|c|}{ Pulmonary embolism } & \multicolumn{2}{|c|}{ Deep vein thrombosis } & \multirow{2}{*}{$\begin{array}{l}\text { Rate ratio } \\
(95 \% \mathrm{Cl})\end{array}$} \\
\hline & $\bar{N}$ & $\begin{array}{l}\text { Events per } 100 \\
\text { patient-years }\end{array}$ & $\bar{N}$ & $\begin{array}{l}\text { Events per } 100 \\
\text { patient-years }\end{array}$ & \\
\hline Patients, N & 14 & & 9 & & \\
\hline Recurrent PE & 0 & - & 0 & - & - \\
\hline Recurrent DVT & 0 & - & 1 & $16.67(0.22-92.72)$ & - \\
\hline Major bleeding & 1 & $10.02(0.13-55.75)$ & 1 & $16.67(0.22-92.72)$ & $0.60(0.04-9.61)$ \\
\hline \multicolumn{6}{|l|}{ Site of major bleeding (days) ${ }^{a}$, } \\
\hline Epistaxis $\left(32^{\mathrm{b}}\right)$ & 0 & - & 1 & $16.67(0.22-92.72)$ & - \\
\hline Gl (534) & 1 & $10.02(0.13-55.75)$ & 0 & - & - \\
\hline Non-major bleeding & 3 & $30.06(6.04-87.83)$ & 3 & $50(10.05-146.1)$ & $0.60(0.12-2.98)$ \\
\hline \multicolumn{6}{|l|}{ Site of minor bleeding (days) $)^{a}$, } \\
\hline Epistaxis $(9,31,179)$ & 3 & $30.06(6.04-87.83)$ & 0 & - & - \\
\hline Others $\left(0^{\mathrm{b}}, 5,50\right)$ & 0 & - & 3 & $50(10.05-146.1)$ & - \\
\hline Death & 1 & $10.02(0.13-55.75)$ & 0 & - & - \\
\hline \multicolumn{6}{|l|}{ Causes of death, } \\
\hline Respiratory insufficiency & 1 & $10.02(0.13-55.75)$ & 0 & - & - \\
\hline
\end{tabular}

Abbreviations: PE pulmonary embolism, DVT deep vein thrombosis; $95 \% \mathrm{Cl}, 95 \%$ confidence intervals, Gl gastrointestinal

${ }^{\text {a }}$ Days from index VTE diagnosis to bleeding event

${ }^{b}$ Receiving LMWH $<100$ IU/kg/day 
Eighteen patients in our cohort (78\%) had prior epistaxis, five had renal insufficiency, three had documented angiodisplasia in the GI tract and one patient had a gastroduodenal ulcer. To what extent the use of anticoagulant therapy could have influenced on the risk for bleeding is unknown. Two of the three patients with major epistaxis in the 30 days before the index VTE repeated epistaxis during the course of anticoagulation: one of these had a major re-bleeding. Then, we cannot assume that repeated epistaxis that happened during the course of anticoagulant therapy were exclusively related to anticoagulation, as epistaxis is an inherent feature of HHT $[3,4,9]$. However, anticoagulation can increase the duration and severity of epistaxis [12]. Unfortunately, we have no monitoring ESS during anticoagulant treatment to analyze this association.

In spite of the bleeding risk, some HHT patients also suffer from thrombotic complications [10, 25-27]. Six patients in our cohort developed the index VTE after being immobilized for an acute medical illness and two had recent surgery, but only three of them did receive VTE prophylaxis. We hypothesize that the attending doctors might have been concerned about the risk for bleeding. In the on-line survey of HHT patients with self-reported VTE, $76 \%$ of them had a risk factor for VTE [13]. There is consistent evidence on the reduction of VTE using prophylaxis in at-risk patients, with very low increase in the risk for bleeding [28], but we do not know the potential benefit of VTE prophylaxis in at-risk patients with HHT. Further research is necessary to define prophylactic strategies in this frequently hospitalized HHT population. For these provoked VTE events, anticoagulant therapy for only 3 months is recommended [29].

Our study has a number of limitations. First, the proportion of patients with HHT in our cohort was most likely conservative because some cases might have been missed. Second, we were not able to retrospectively collect genetic study and reassess Curaçao criteria in all patients $[7,8]$. Nonetheless, the high percentage of recurrent epistaxis and first degree relatives with HHT in our patients, support the HHT diagnosis. Third, our study was not designed for assessment of comparative effectiveness of management strategies in patients with HHT. Since all patients with HHT in our cohort received anticoagulant therapy, we are unable to compare the potential advantages of the different therapeutic approaches. However, our study provides important insights into the outcomes of HTT patients with VTE. Fourth, the ESS has been retrospectively calculated after some time, being a likely cause of ascertainment bias. Finally, although many of the studies from the RIETE registry were designed with broad or detailed a priori plans, HHT is a rare disease and the decisions to explore several of the data elements were based on post-hoc plans and analyses. However, to our knowledge, these data represent the largest series of patients with HHT and objectively confirmed VTE. Moreover, the main strengths of our study are the strict and objectively diagnostic criteria for VTE, the long-term follow-up period and the objectively established outcomes reported (bleeding, recurrent symptomatic VTE and mortality).

\section{Conclusions}

In conclusion, the use of anticoagulant therapy for VTE in patients with HHT may certainly increase the risk for bleeding, but it barely influences on mortality. Most bleeds come from nasal or digestive telangiectasia and not from large HHT-related vascular malformations. So, although bleeding events are more frequent than VTE recurrences, the use of anticoagulation was not associated with fatal bleeding. PE is the most common presentation of VTE in patients with HHT. Almost half of our HHT patients had a risk factor for VTE. Patients with HHT should be carefully evaluated for nosebleeds when needing anticoagulant treatment. The optimal type, dose and duration of anticoagulant therapy for VTE in patients with HHT needs further investigation.

\section{Abbreviations \\ 95\%Cl: 95\% confidence interval; ACVRL1: Activin A receptor type II-like 1 gene; $\mathrm{CrCl}$ : Creatinine clearance; DVT: Deep venous thrombosis; \\ ENG: Endoglin gene; ESS: Epistaxis Severity Score; GI: Gastrointestinal; HHT: Hereditary hemorrhagic telangiectasia; IQR: Interquartile range; \\ IU: international units; LMWH: Low-molecular-weight heparin; OR: Odds ratio; PE: Pulmonary embolism; RIETE: Registro Informatizado Enfermedad TromboEmbólica; SD: Standard deviation; SPESI: simplified Pulmonary Embolism Severity Index; TGF: Transforming growth factor; VKAs: Vitamin K antagonists; VTE: Venous thromboembolism}

\section{Acknowledgements}

We thank the RIETE Registry Coordinating Center, S\&H Medical Science Service, for their quality control data, logistic and administrative support and Prof. Salvador Ortiz, Universidad Autónoma Madrid and Silvia Galindo, both Statistical Advisors in S\&H Medical Science Service for the statistical analysis of the data presented in this paper.

Coordinator of the RIETE Registry: Manuel Monreal.

RIETE Steering Committee Members: Paolo Prandoni, Benjamin Brenner and Dominique Farge-Bancel.

RIETE National Coordinators: Raquel Barba (Spain), Pierpaolo Di Micco (Italy), Laurent Bertoletti (France), Sebastian Schellong (Germany), Inna Tzoran (Israel), Abilio Reis (Portugal), Marijan Bosevski (R. Macedonia), Henri

Bounameaux (Switzerland), Radovan Malý (Czech Republic), Peter Verhamme (Belgium), Joseph A. Caprini (USA), Hanh My Bui (Vietnam).

RIETE Registry Coordinating Center: S \& H Medical Science Service. Members of the RIETE Group:

SPAIN: Adarraga MD, Agud M, Aibar MA, Alcalde-Manero M, Alfonso J, Amado C, Arcelus Jl, Ballaz A, Barba R, Barbagelata C, Barrón M, BarrónAndrés B, Blanco-Molina A, Camon AM, Cañas I, Castro J, Cerdà P, de Miguel J, del Toro J, Demelo P, Díaz-Pedroche C, Díaz-Peromingo JA, Domínguez IM, Escribano JC, Falgá C, Fernández-Capitán C, Fernández-Criado MC, Fidalgo MA, Flores K, Font C, Font L, Furest I, García MA, García-Bragado F, GarcíaRaso A, Gavín-Blanco O, Gavín-Sebastián O, Gil-Díaz A, Godoy-Díaz D, Gómez V, Gómez-Cuervo C, González-Martínez J, Grau E, Guirado L, Gutiérrez J, Hernández-Blasco LM, Jara-Palomares $L$, Jaras MJ, Jiménez $D$, Joya MD, Jou I,

Lalueza A, Lecumberri R, Lima J, Llamas P, Lobo JL, López-Jiménez L, LópezMeseguer M, López-Miguel P, López-Núñez JJ, López-Reyes R, López-Sáez JB, Lorente MA, Loring M, Lumbierres M, Madridano O, Maestre A, Marchena PJ, 
Martín-Martos F, Martínez-Baquerizo C, Martínez-García MA, Mellado M, Moisés J, Monreal M, Morales MV, Muñoz-Blanco A, Nieto JA, Núñez MJ, Olivares MC, Olivera PE, Ortega C, Osorio J, Otalora S, Otero R, Panadero-Macia M, Parra V, Pedrajas JM, Pellejero G, Pérez-Ductor C, Pérez-Rus G, Peris ML, Pesantez D, Porras JA, Riera-Mestre A, Rivas A, Rodríguez-Cobo A, RodríguezMatute C, Rosa V, Rubio CM, Ruiz-Artacho P, Ruiz-Sada P, Sahuquillo JC, SalaSainz MC, Salgueiro G, Sampériz A, Sánchez-Martínez R, Sánchez-Muñoz-Torrero JF, Seguí E, Soler S, Suárez S, Suriñach JM, Tolosa C, Torres MI, TrujilloSantos J, Uresandi F, Valero B, Valle R, Vidal G, Vilar C, Villares P, ARGENTINA: Gutiérrez P, Vázquez FJ, Vilaseca A, BELGIUM: Vanassche T, Vandenbriele C, Verhamme P, CZECH REPUBLIC: Hirmerova J, Malý R, ECUADOR: Salgado E, FRANCE: Benzidia I, Bertoletti L, Bura-Riviere A, Debourdeau P, Courtois MC, Farge-Bancel D, Helfer H, Hij A, Mahé I, Moustafa F, GERMANY: Schellong S, ISRAEL: Braester A, Brenner B, Tzoran I, ITALY: Bilora F, Bortoluzzi C, Ciammaichella M, Dentali F, Di Micco P, Ferrazzi P, Imbalzano E, Lodigiani C, Maida R, Mastroiacovo D, Mumoli N, Pace F, Pesavento R, Pomero F, Prandoni P, Quintavalla R, Rocci A, Rota L, Siniscalchi C, Tiraferri E, Tufano A, Visonà A, Vo Hong N, Zalunardo B, LATVIA: Kalejs RV, Kigitovica D, Skride A, REPUBLIC OF MACEDONIA: Bosevski M, Zdraveska M, SWITZERLAND: Bounameaux H, Mazzolai L, USA: Caprini JA, Tafur AJ, VIETNAM: Bui HM.

\section{Authors' contributions}

ARM and MM conceived and designed the study. ARM, JMML, JTS, JDT, JAN, JMP, RLR, SS, AB, PC, MM and the RIETE Investigators, acquired clinical data. ARM and JTS, performed statistical analysis. ARM, JMML, JTS, PC and MM, interpreted results and drafted the manuscript. All authors performed critical revisions, and read and approved the final version of the manuscript. ARM, JMML, JTS and MM, had full access to all data in the study, and take responsibility for the integrity of the data and the accuracy of data analysis.

\section{Funding}

Sanofi support this Registry with an unrestricted educational grant.

\section{Availability of data and materials}

The datasets used and/or analysed during the current study are available from the corresponding author on reasonable request.

\section{Ethics approval and consent to participate}

This study was approved by the local Ethical Committees of the concerned hospitals and was conducted in accordance with the principles of the Helsinki Declaration. All patients (or their relatives) provided written or oral consent for participation in the registry, according to local Ethical Committees requirements.

\section{Consent for publication}

This manuscript does not contain any individual person's data in any form. Each patient was identified by a unique alphanumeric identification code and all data were made anonymous and analysed as aggregates.

\section{Competing interests}

The authors declare that they have no competing interests.

\section{Author details}

${ }^{1}$ HHT Unit and VTE Unit, Internal Medicine Department, Hospital Universitari de Bellvitge, Bellvitge Biomedical Research Institute (IDIBELL), C/ Feixa Llarga s/n. L'Hospitalet de Llobregat, 08907 Barcelona, Spain. ${ }^{2}$ Faculty of Medicine and Health Sciences, Universitat de Barcelona, Barcelona, Spain. ${ }^{3}$ Department of Internal Medicine, Hospital General Universitario Santa Lucía, Cartagena, Universidad Católica de Murcia, Murcia, Spain. ${ }^{4}$ Department of Internal Medicine, Hospital General Universitario Gregorio Marañón, Madrid, Spain. ${ }^{5}$ Department of Internal Medicine, Hospital General Virgen De La Luz, Cuenca, Spain. ${ }^{6}$ Department of Internal Medicine, Hospital Clínico San Carlos, Madrid, Spain. ${ }^{7}$ Department of Pneumonology, Hospital Universitari i Politècnic La Fe, Valencia, Spain. ${ }^{8}$ Department of Internal Medicine, Fundació Hospital d'Olot i Comarcal de la Garrotxa, Gerona, Spain. ${ }^{9}$ Department of Pneumonology, Hospital De Galdakao, Galdakao, Vizcaya, Spain. ${ }^{10}$ Department of Internal Medicine, Hospital Germans Trias i Pujol Badalona, Barcelona, Universidad Autónoma de Barcelona, Barcelona, Spain.
Received: 23 May 2019 Accepted: 30 July 2019

Published online: 09 August 2019

\section{References}

1. Shovlin CL, Buscarini E, Kjeldsen AD, Mager HJ, Sabba C, Droege F, et al. European reference network for rare vascular diseases (VASCERN) outcome measures for hereditary Haemorrhagic telangiectasia. Orphanet J Rare Dis. 2018;13:136.

2. McDonald J, Wooderchak-Donahue W, VanSant Webb C, Whitehead K, Stevenson DA, Bayrak-Toydemir P. Hereditary hemorrhagic telangiectasia: genetics and molecular diagnostics in a new era. Front Genet. 2015;6:1.

3. Faughnan ME, Palda VA, Garcia-Tsao G, Geisthoff UW, McDonald J, Proctor DD, et al. HHT Foundation International - guidelines working group. International guidelines for the diagnosis and management of hereditary haemorrhagic telangiectasia. J Med Genet. 2011;48:73-87.

4. Riera-Mestre A, Ribas J, Castellote J. Medical management of haemorrhagic hereditary telangiectasia in adult patients. Med Clin (Barc). 2019;152:274-80.

5. Garcia-Tsao G. Liver involvement in hereditary hemorrhagic telangiectasia. J Hepatol. 2007;46:499-507.

6. Voselaars VM, Velthius S, Snijder RJ, Westermann CJ, Vos JA, Mager JJ, et al. Follow-up of pulmonary right-to-left shunt in hereditary haemorrhagic telangiectasia. Eur Respir J. 2016:47:1750-7.

7. Shovlin CL, Guttmacher AE, Buscarini E, Faughnan ME, Hyland RH, Westermann CJ, et al. Diagnostic criteria for hereditary hemorrhagic telangiectasia (Rendu-Osler-weber syndrome). Am J Med Genet. 2000;91:66.

8. Alsina-Sanchís E, García-lbáñez Y, Fiqueiredo AM, Riera-Domingo C, Figueras A, Matias-Guiu X, et al. ALK1 loss results in vascular hyperplasia in mice and humans through PI3K activation. Arterioscler Thromb Vasc Biol. 2018;38: 1216-29.

9. Riera-Mestre A, Mora Luján JM, Sanchez Martínez R, Torralba Cabeza MA. Patier de la Peña $J$, Juyol Rodrigo MC, et al, on behalf of the researchers of the RiHHTa registry. Computerized registry of patients with hemorrhagic hereditary telangiectasia (RiHHTa registry) in Spain: objectives, methods, and preliminary results. Rev Clin Esp. 2018;218:468-76.

10. Shovlin CL, Sulaiman NL, Govani FS, Jackson JE, Begbie ME. Elevated factor VIII in hereditary haemorrhagic telangiectasia (HHT): association with venous thromboembolism. Thromb Haemost. 2007;98:1031-9.

11. Livesey JA, Manning RA, Meek JH, Jackson JE, Kulinskaya E, Laffan MA, et al. Low serum iron levels are associated with elevated plasma levels of coagulation factor VIII and pulmonary emboli/deep venous thromboses in replicate cohorts of patients with hereditary haemorrhagic telangiectasia. Thorax. 2012;67:328-33.

12. Devlin HL, Hosman AE, Shovlin CL. Antiplatelet and anticoagulant agents in hereditary hemorrhagic telangiectasia. N Engl J Med. 2013;368:876-8.

13. Chaturvedi S, Kohli R, Schaefer N, Clancy M, Kasthuri RS. Characteristics and outcomes of venous thromboembolism in patients with hereditary hemorrhagic telangiectasia. Thromb Res. 2018;169:41-3.

14. Nieto JA, Camara T, Gonzalez-Hiqueras E, Ruiz-Gimenez N, Guijarro R, Marchena PJ, et al. Clinical outcome of patients with major bleeding after venous thromboembolism. Findings from the RIETE Registry. Thromb Haemost. 2008;100:789-96.

15. Jiménez D, Aujesky D, Moores L, Gómez V, Lobo JL, Uresandi F, et al. Simplification of the pulmonary embolism severity index for prognostication in patients with acute symptomatic pulmonary embolism. Arch Intern Med. 2010;170:1383-9.

16. Riera-Mestre A, Jiménez D, Muriel A, Lobo JL, Moores L, Yusen RD, et al; RIETE investigators. Thrombolytic therapy and outcome of patients with an acute symptomatic pulmonary embolism. J Thromb Haemost. 2012;10:7519.

17. Bikdeli B, Sharif-Kashani B, Bikdeli B, Valle R, Falga C, Riera-Mestre A, et al. RIETE investigators. Impact of Thrombus sidedness on presentation and outcomes of patients with proximal lower extremity deep vein thrombosis. Semin Thromb Hemost. 2018;44:341-7.

18. von Elm E, Altman DG, Egger M, Pocock SJ, Gøtzsche PC, Vandenbroucke JP;STROBE initiative. Strengthening the reporting of observational studies in epidemiology (STROBE) statement: guidelines for reporting observational studies. BMJ. 2007:335:806-8

19. Hoag JB, Terry P, Mitchell S, Reh D, Merlo CA. An epistaxis severity score for hereditary hemorrhagia telangiectasia. Laryngoscope. 2010;120:838-43.

20. Morais D, Millás T, Zarrabeitia R, Botella LM, Almaraz A. Local sclerotherapy with polydocanol (Aethoxysklerol ${ }^{\oplus}$ ) for the treatment of epistaxis in Rendu- 
Osler-weber or hereditary hemorrhagic telangiectasia (HHT): 15 years of experience. Rhinology. 2012;50:80-6.

21. Gaillard $S$, Dupuis-Girod $S$, Boutitie F, Rivière $S$, Morinière $S$, Hatron PY, et al. ATERO study group. Tranexamic acid for epistaxis in hereditary hemorrhagic telangiectasia patients: a European cross-over controlled trial in a rare disease. J Thromb Haemost. 2014;12:1494-502.

22. Yaniv E, Preis M, Shevro J, Nageris B, Hadar T. Anti-estrogen therapy for hereditary hemorrhagic telangiectasia - a long-term clinical trial. Rhinology. 2011:49:214-6

23. Invernizzi R, Quaglia F, Klersy C, Pagella F, Ornati F, Chu F, et al. Efficacy and safety of thalidomide for the treatment of severe recurrent epistaxis in hereditary haemorrhagic telangiectasia: results of a non-randomised, singleCentre, phase 2 study. Lancet Haematol. 2015;2:e465-73.

24. Buscarini E, Botella LM, Geisthoff U, Kjeldsen AD, Mager HJ, Pagella F, et al. Safety of thalidomide and bevacizumab in patients with hereditary hemorrhagic telangiectasia. Orphanet J Rare Dis. 2019;14(1):28.

25. Dittus C, Streiff $M$, Ansell J. Bleeding and clotting in hereditary hemorrhagic telangiectasia. World J Clin Cases. 2015;3:330-7.

26. Jenkins PV, Rawley O, Smith OP, O'Donnell JS. Elevated factor VIII levels and risk of venous thrombosis. Br J Haematol. 2012;157:653-63.

27. Shovlin CL, Chamali B, Santhirapala V, Livesey JA, Angus G, Manning R, et al. Ischaemic strokes in patients with pulmonary arteriovenous malformations and hereditary hemorrhagic telangiectasia: associations with iron deficiency and platelets. PLoS One. 2014;9:e88812.

28. Alikhan R, Bedenis R, Cohen AT. Heparin for the prevention of venous thromboembolism in acutely ill medical patients (excluding stroke and myocardial infarction). Cochrane Database Syst Rev. 2014;5:CD003747.

29. Kearon C, Akl EA, Ornelas J, Blaivas A, Jimenez D, Bounameaux H, et al. Antithrombotic therapy for VTE disease: CHEST guideline and expert panel report. Chest. 2016;149:315-52

\section{Publisher's Note}

Springer Nature remains neutral with regard to jurisdictional claims in published maps and institutional affiliations.

Ready to submit your research? Choose BMC and benefit from:

- fast, convenient online submission

- thorough peer review by experienced researchers in your field

- rapid publication on acceptance

- support for research data, including large and complex data types

- gold Open Access which fosters wider collaboration and increased citations

- maximum visibility for your research: over $100 \mathrm{M}$ website views per year

At $\mathrm{BMC}$, research is always in progress.

Learn more biomedcentral.com/submissions 